\title{
Tafelfonds.
}

\section{$X$. Bericht.}

Nach dem letzten Bericht (J. f. O. 1936, p. 692) verblieb ein angedeckter Betrag von . . . . . . . . . . . . . $173386 \mathrm{RM}$

A) Einnahmen:

Es stifteten seitdem

Seine Majestät König Ferdinand . . . . . . 100.- RM

Dr. E. Mosler . . . . . . . . . . . . . 100." "

Dr. Winkler . . . . . . . . . . . . . 100.-"

Dr. Heinroth . . . . . . . . . . . . . 100-"

Frau Rauter . . . . . . . . . . . . . . 50.-"

F. Tischler . . . . . . . . . . . . . . 20,- "

Dr. Gerh. Niethammer . . . . . . . . . . 15.-"

Dr. Schüz , . . . . . . . . . . . . . . 15- "

Prof. Dr. F. Steinbacher . . . . . . . . . 5.- "

Dr. Brunotte . . . . . . . . . . . . . . 5.- "

Dr. Heckmann . . . . . . . . . . . . . 5. "

H. Schumann . . . . . . . . . . . . . 3.-,

Dr. Jaeckel . . . . . . . . . . . . . . 3.-"

Dr. Kuhk . . . . . . . . . . . . . . . 3.-"

R. Schöttle . . . . . . . . . . . . . . 3.- "

Dr. Wachs . . . . . . . . . . . . . . 3.- "

Dr. Hartmann (Kassel) . . . . . . . . . . 3.- "

E. Müller-Prag . . . . . . . . . . . . . 2.25 "

Dr. v. Boetticher . . . . . . . . . . . . 2.- "

G. v. Bruchhausen. . . . . . . . . . . . 2.- "

W. Salzmann . . . . . . . . . . . . . . 1.50 "

H. Pönitz . . . . . . . . . . . . . . 1.50 "

Ungenannt . . . . . . . . . . . . . . $\frac{1.51}{543.76 \mathrm{RM}}$

Damit ergab sich ein Kassenbestand von . . . . 369.90 RM

B) An Ausgaben stehen dem gegenüber:

Herstellung der Tafel I von Lobiophasis bulweri . . 320.- RM

der Tafeln II-IX von Caprimulgus europaeus · · $\frac{499.25 \mathrm{RM}}{819.25 \mathrm{RM}}$

C) Saldo:

Es verbleibt demnach ein noch ungedeckter Betrag von

Wir bitten unsere Mitglieder, sich an der Deckang des Fehlbetrages durch gitige Spenden zu beteiligen, da ohne freiwillige Beihilfen die Beigabe von Tafeln zum Journal für Ornithologie bedanerlicherweise erheblich eingeschränkt werden müßte. 